MATEC Web of Conferences 6, 04001 (2013)

DOI: $10.1051 /$ matecconf/20130604001

(C) Owned by the authors, published by EDP Sciences, 2013

\title{
Large scale fire test on tunnel segment: Real boundary conditions in order to evaluate spalling sensitivity and fire resistance
}

\author{
F. Robert, C. Collignon and M. Scalliet
}

\author{
CERIB, Epernon, France
}

\begin{abstract}
The objective of the present study was to reproduce the real state of stress in a tunnel segment in order to evaluate the spalling sensivity. Numerical tools have been used to predict the restrained axial forces which may appear due to the thermal expansion. A new experimental set up has been designed to withstand these forces. Thus the choice of a protected self-resistant slab to reproduce the surroundings has been done to test the loaded precast tunnel segment which withstood a two hour modified hydrocarbon fire with only limited amount of spalling.
\end{abstract}

\section{INTRODUCTION}

When modified hydrocarbon fire curve (HCM curve) is the specified thermal action in a project, then the only way to give evidence on the fire resistance is to perform a fire test. Indeed, for the time being, the numerical tools are not able to predict the spalling phenomena. On the other end, attention should be paid to the boundary conditions of the fire test itself as we know that the mechanical loading could have a great influence on the spalling phenomenon. In particular, the way the compressive stress due to the hindered thermal expansion, will develop on the intrados of the tunnel segment can lead to extremely different results in terms of spalling probability.

In the present study, a first step was dedicated to the numerical analysis of the boundary conditions and to the assessment of the hindered thermal expansion in the intrados of the tunnel segment. Taking into account the results of this first step, a test set up has been designed. Then the test has been performed under a two hour modified hydrocarbon fire curve and finally spalling sensitivity has been assessed through innovative measurement procedure.

\section{STUDIED TUNNEL SEGMENT CHARACTERISTICS}

The studied segment is a current one of a ring for a tunnel built in 2011 in France. The characteristics of the segment are as follows:

- the radius of the intrados is $4175 \mathrm{~mm}$,

- the thickness is $370 \mathrm{~mm}$,

- the arc of the underside (intrados) is $3498 \mathrm{~mm}$

- the arc of the top surface (extrados) is $3808 \mathrm{~mm}$.

- the segment is $1800 \mathrm{~mm}$ in width.

The tunnel segment has been stored $\left(50 \% \mathrm{RH}, 23^{\circ} \mathrm{C}\right)$ during 5 months after casting before the fire test. The mean concrete compressive strength was $91.5 \mathrm{MPa}$ (on $15 \mathrm{~cm}$ side cubes) and the moisture content

This is an Open Access article distributed under the terms of the Creative Commons Attribution License 2.0, which permits unrestricted use, distribution, and reproduction in any medium, provided the original work is properly cited. 


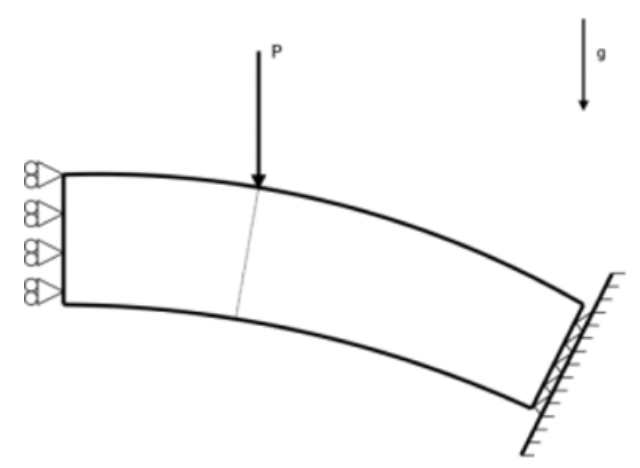

Figure 1. Kinematics conditions.

was $3.1 \%$ when the fire test was performed (on cylindrical samples $\varnothing 16 \mathrm{~cm}, \mathrm{l}=32 \mathrm{~cm}$ ) $\cdot 2 \mathrm{~kg} / \mathrm{m}^{3}$ of monofilament propylene fibres whose length was $12 \mathrm{~mm}$ have been added to the concrete mix.

\section{NUMERICAL ANALYSIS OF THE STRESS STATE}

\subsection{Description of the model}

The tunnel segment has been modeled thanks to Castem Software. A simplified approach has been adopted by choosing a 2D element with a behavioural assumption of plane stress. Indeed the test configuration will allow some deformation on the longitudinal edge of the tunnel segment. This assumption would not have been the same in a full scale tunnel for which a behavioural assumption of plane strain would have been selected. The following figure (Fig. 1) shows the kinematics conditions which have been adopted (different conditions have been analysed before to adopt them): symmetry plan at mid-span of the tunnel segment, slab/tunnel segment contact with a friction coefficient of 0.3 . Moreover, the edge is free to rotate.

On a first step, a nonlinear thermal simulation is performed (all the thermal properties are defined in accordance with EN 1992-1-2 [1]). Then the mechanical calculation is achieved taking into account the temperature through the thermal expansion and the decrease of the Young modulus. Concrete is modeled as an elastic isotropic material.

During the test, the loading of the segment is carried out through two lines of two hydraulic jacks each for a total of 90 tonnes (22.5 tonnes per jack). The level of loading has been defined in order to find the stress state the most similar according to the design at ambient temperature: a compressive stress state corresponding to an axial force of $1408 \mathrm{kN}$.

\subsection{Results of the numerical modeling}

Before the fire test, the resulting axial force is a compressive one even if the intrados of the tunnel is slightly in tension (see Fig. 2). As soon as the segment is sumitted to the fire, the thermal expansion will lead to the developement of a compressive bell-shaped zone next to the heated surface. The top of this bell-shaped zone reaches a maximum stress level of about $20 \mathrm{MPa}$. During the heating process, this zone will gradually move away from the heated surface whereas a tension area will extend on the unexposed surface. Due to the simplified model adopted which considers an elastic isotropic material, the tension level will grow up to $12 \mathrm{MPa}$ after two hours of a modified hydrocarbon exposure whereas some cracks should appear to release these tensile stress. 
IWCS 2013

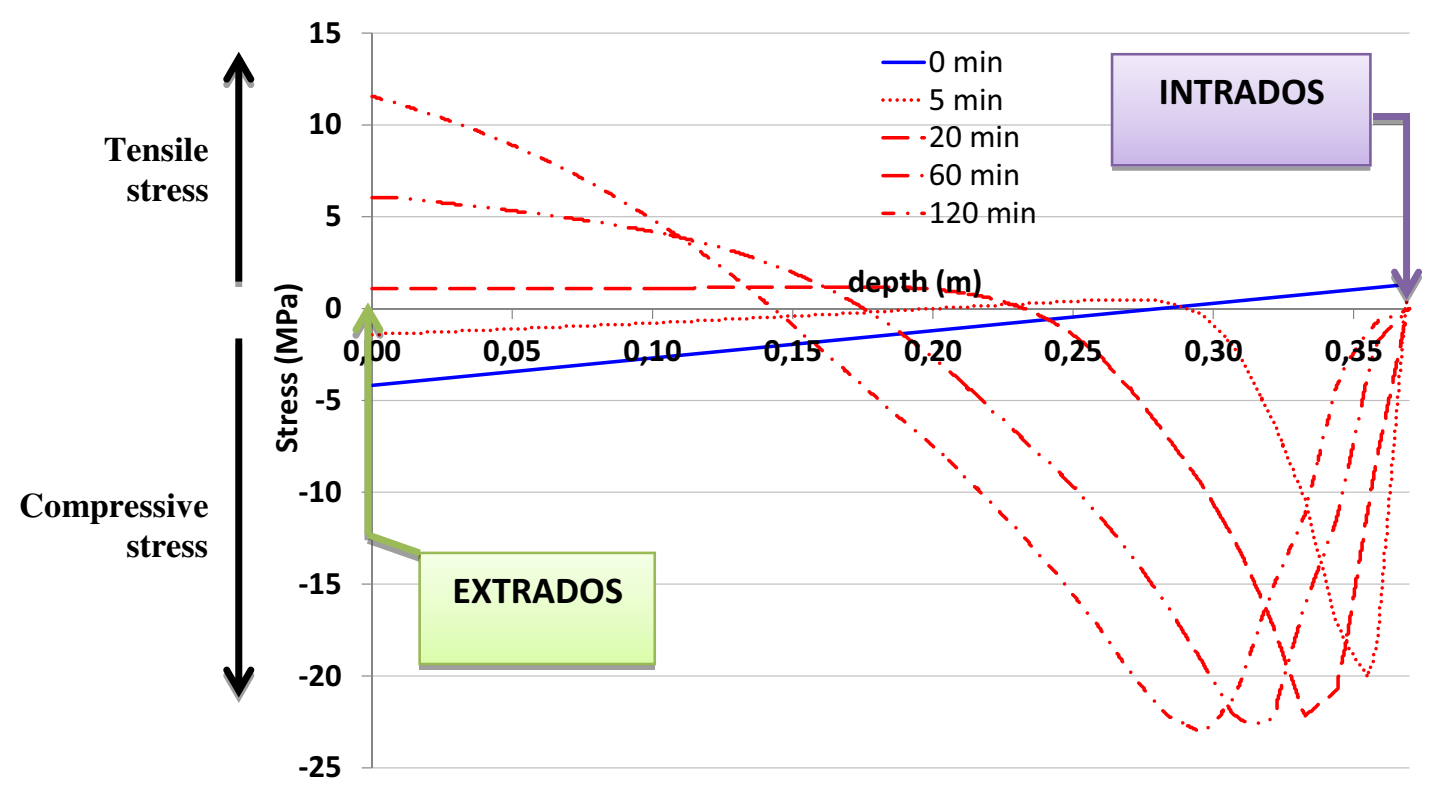

Figure 2. Stress state at the tunnel segment keystone.

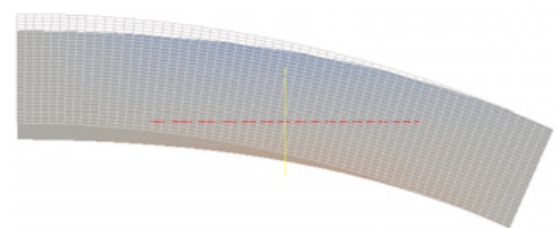

(a) After loading, before the fire test

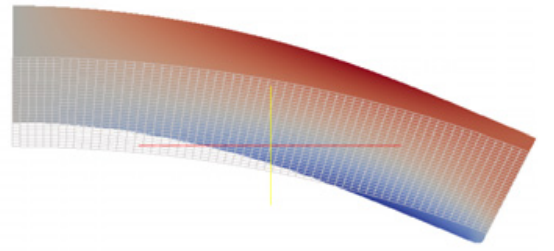

(b) After 2 hours HCM exposure

Figure 3. Strain state at the tunnel segment keystone.

The horizontal reactive force is about 100 tonnes before the test after loading. Due to the restrainment of the thermal expansion, the horizontal reactive force will grow up to 270 tonnes after the two hours of a modified hydrocarbon exposure.

With regard to the deformation of the segment (Fig. 3), it appears that the tunnel segment will slightly lift oneself up during the test (numerically, a $2 \mathrm{~mm}$ lifting is observed at the keystone of the tunnel segment) after 2 hours HCM exposure.

\section{TEST SET UP}

\subsection{Description of the test set up}

In order to reproduce the real boundary conditions of the tunnel segment during a fire and to withstand the generated forces due to thermal expansion, a specific set up has been designed. It consists of a protected self-resistant slab in reinforced concrete with an opening at its center whose sides are at a bit of an angle in order to perfectly support the specific shape of the segment (the sides are inclined at an angle of $24^{\circ}$ ). When the segment is positioned in the center of the slab, a VEDAFEU fire stop system is laid at the bottom of the transversal joint between the slab and the tunnel segment. A Neoprene is 

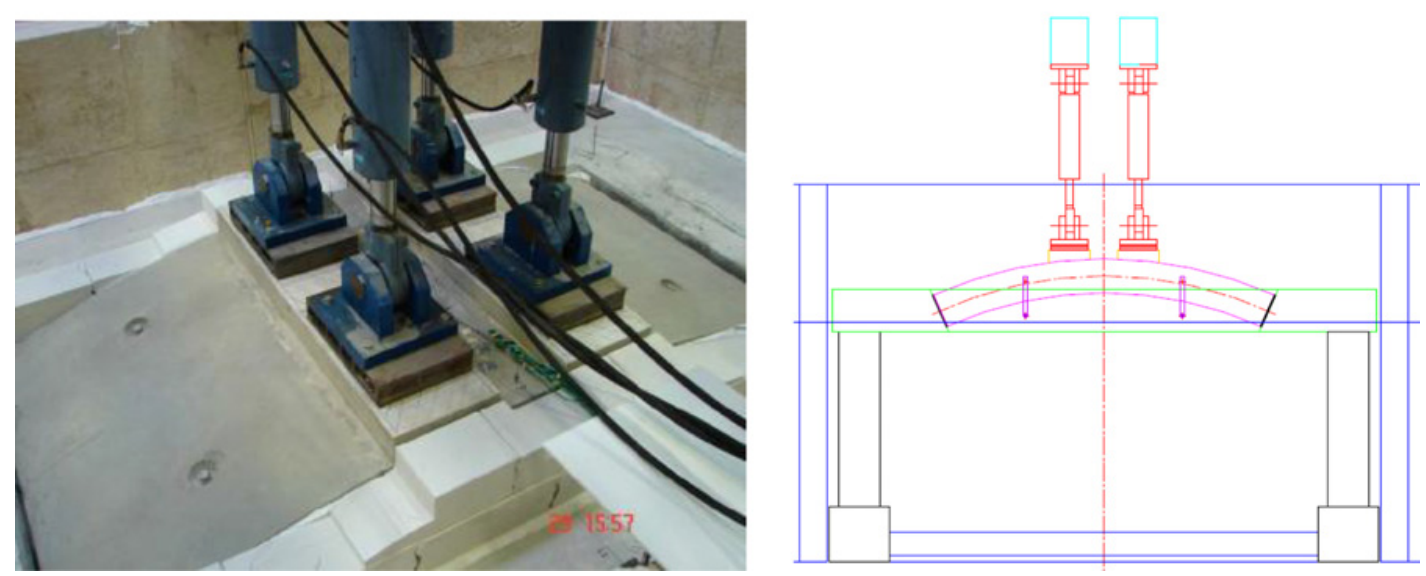

Figure 4. Test set up used for a precast tunnel lining $37 \mathrm{~cm}$ depth.
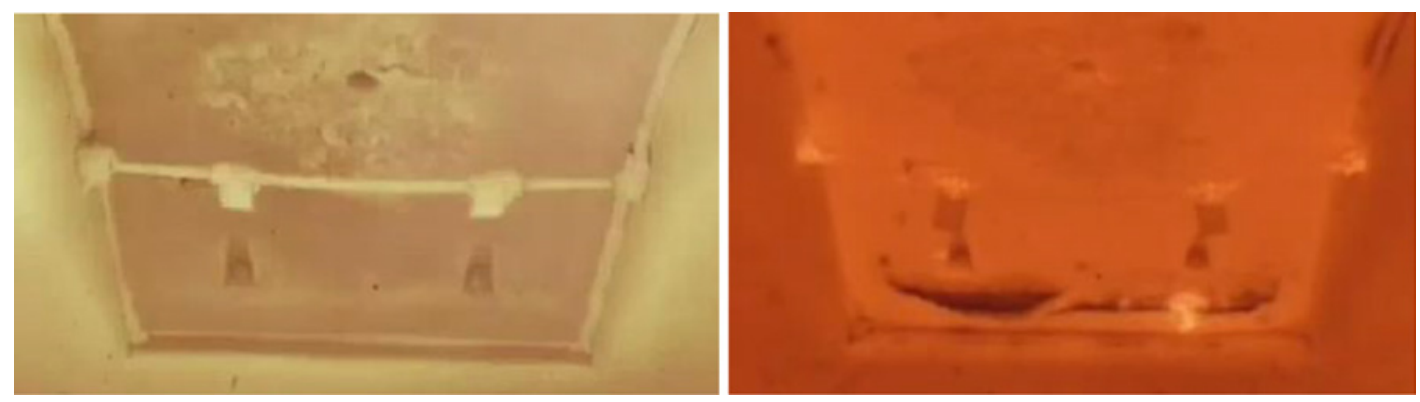

Figure 5. Exposed surface at the $4^{\text {th }}$ minute (left) and at the $122^{\text {nd }}$ minute (right).

inserted on the side of the slab and then the transversal joints are filled with a specific mortar. Some mineral wool fills the longitudinal joints (the transversal forces are considered not to be significant as there is no continuous contact between the rings).

The loads are applied through a base cast in concrete to counterbalance the circular shape of the segment (Fig. 4).

\subsection{Fire exposure}

The modified hydrocarbon temperature-time curve is given by:

$$
\Theta_{\mathrm{g}}=1280\left(1-0.325 e^{-0.167 \mathrm{t}}-0.675 e^{-2.5 \mathrm{t}}\right)+20\left[{ }^{\circ} \mathrm{C}\right] .
$$

Where $\quad \Theta_{\mathrm{g}}$ is the gas temperature in the fire compartment $\left[{ }^{\circ} \mathrm{C}\right]$

$$
\mathrm{t} \text { is the time [min]. }
$$

The thermal running of the test is ensured thanks to plate thermometers.

\subsection{Temperature profile}

After a two hour modified hydrocarbon curve exposure, the temperature inside the reinforced concrete tunnel segment has been registered at $950{ }^{\circ} \mathrm{C}$ at $2 \mathrm{~cm}$ from the exposed surface, at $690^{\circ} \mathrm{C}$ at $4 \mathrm{~cm}$ from 
(a)

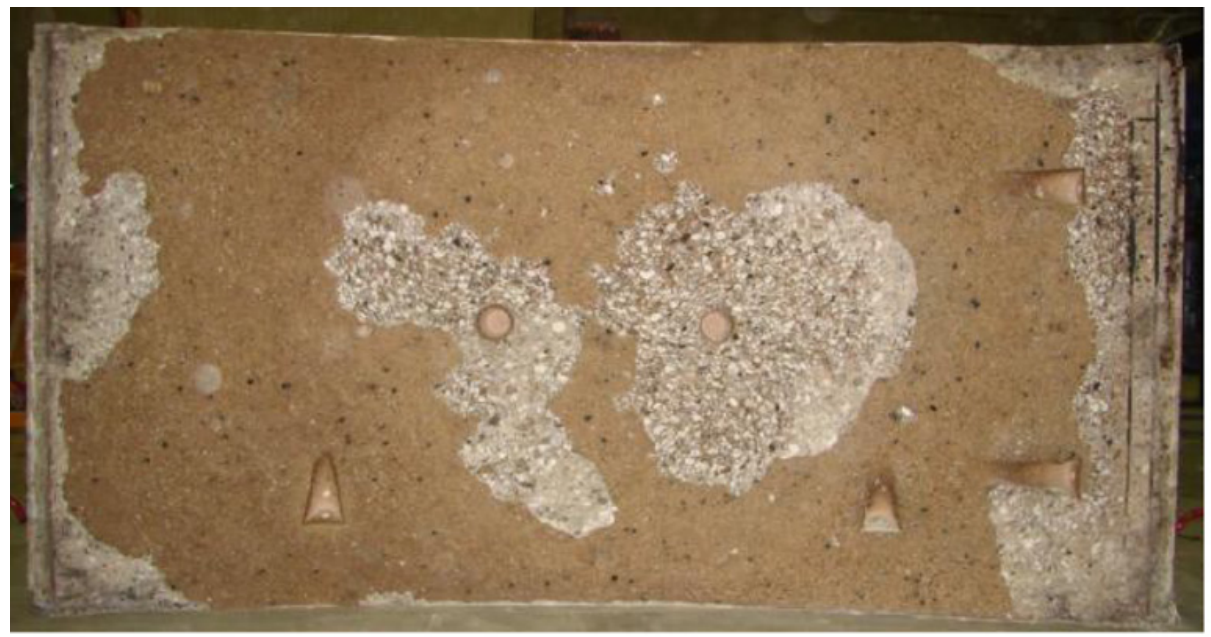

(b)

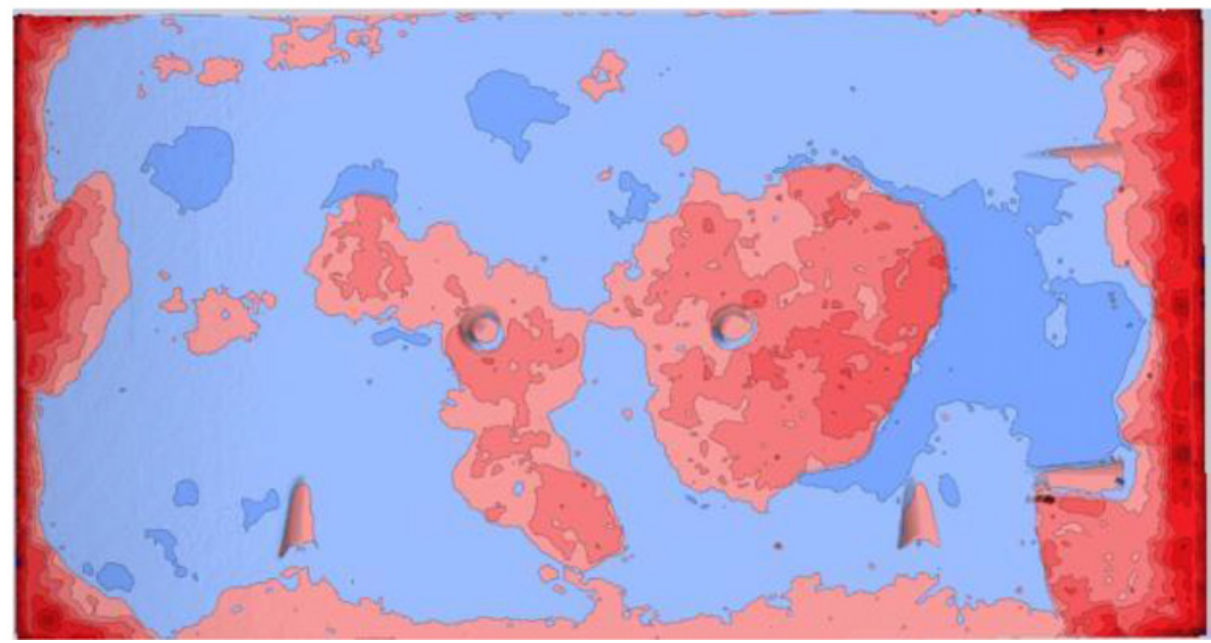

Figure 6. Spalling depth assessment. (a) Picture of the exposed surface; b) digitized exposed surface).

the surface, at $410{ }^{\circ} \mathrm{C}$ at $7 \mathrm{~cm}$ from the surface, at $270{ }^{\circ} \mathrm{C}$ at $10 \mathrm{~cm}$ from the surface and at about $45^{\circ} \mathrm{C}$ on the unexposed surface.

\section{SPALLING MEASUREMENTS}

\subsection{During the test}

The exposed surface of the tunnel segment is observed thanks to a specific camera equipped with an endoscopic system cooled by air and water.

Spalling is observed from the $1^{\text {st }}$ to the $45^{\text {th }}$ minutes of the test. Then, until the end of test (122 minutes), some slight pieces of concrete fall due to cracks those appear near the edge of the segment.

On the unexposed surface, water sweating appears from the $11^{\text {th }}$ minute of the test and continuously until the end of the test. 
MATEC Web of Conferences

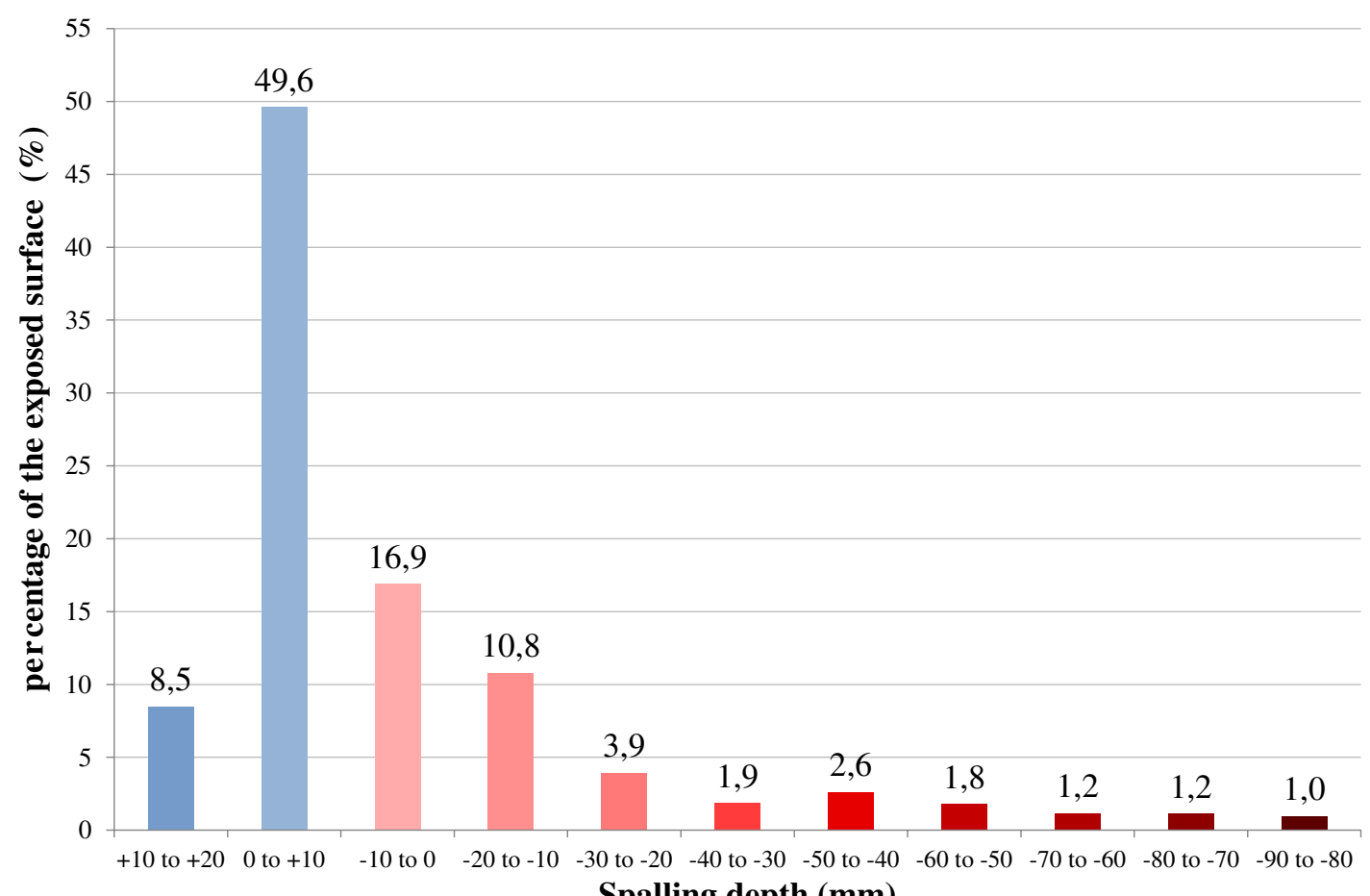

Spalling depth (mm)

Figure 7. Percentage of spalling surface according to spalling depth.

With regard to the deformation/displacement of the tunnel segment during the test, no lifting has been observed nor deflection, as the displacement are not homogeneous on the whole tunnel segment and slab. Anyway the displacement values are of the magnitude of the millimeter.

\subsection{After the test}

The spalling measurement has been performed thanks to a system consisting of a portable 3D video camera that allows to acquire a high density of 3D data of the surface of a sample test before and after test with an accuracy of $0.5 \mathrm{~mm}$. This camera is associated with processing of 3D data and dimensional control software which is capable of producing an image of the spalled surface according to the depth of spalling (Fig. 6).

The rate of spalling is quite low as $40 \%$ of the surface spall but nearly half of this spalled surface has a depth lower than $10 \mathrm{~mm}$ as shown on figure 7. A residual expansion can be observed on the remaining part. A superficial layer about 1 to $3 \mathrm{~cm}$ thick peels off the bottom of the tunnel segment. Some surface aggregates are melted and vitrified.

\section{CONCLUSION}

This last decade, many efforts have been put in order to take into account the indirect fire actions throughout the structure to sharply evaluate the fire resistance of structural element. In the present study, this is achieved through the help of numerical modeling to design the set-up which would be the most representative of the real surrounding conditions. It enables to assure a fire resistance of two hours with the modified hydrocarbon curve without under or overestimating the spalling phenomenon since the right stress state is reproduced. 
IWCS 2013

Moreover, this study has illustrated the capacity to assess very precisely the spalling amount thanks to innovative procedure.

Special thanks are due to the support of STRADAL Company and in particular to Mr. Patrick PELTIER, technical director, for providing the tunnel segment and for encouraging the project.

\section{Reference}

[1] EN 1992-1-2 Eurocode 2: Design of concrete structures - Part 1-2: General rules - Structural fire design (December 2004). 